\title{
A VIOLÊNCIA EM CATEGORIAS DE BASE DO FUTSAL NO RIO DE JANEIRO: UM MERGULHO NO UNIVERSO DOS PAIS E TREINADORES
}

\author{
VIOLENCE IN FUTSAL BASIC AGE CATEGORIES IN RIO DE JANEIRO: \\ ENTERING THE UNIVERSE OF PARENTS AND COACHES
}

\author{
LA VIOLENCIA EN LAS CATEGORÍAS DE BASE DEL FUTSAL EN RIO DE \\ JANEIRO: ENTRANDO EN EL UNIVERSO DE LOS PADRES Y ENTRENADORES
}

\author{
Marcos Fonseca Jorand ${ }^{*}$, Felipe da Silva Triani ${ }^{\star \star}$, Mauricio Murad ${ }^{\star \star *}$, \\ Roberto Ferreira dos Santos ${ }^{\star \star *}$, Silvio de Cassio Costa Telles ${ }^{\star *}$
}

Palavras chave: Esportes.

Futsal.

Torcida.

Violência.

Keywords:

Sports.

Futsal.

Supporter.

Violence.

Palabras clave: Deportes.

Futsal.

Hinchada.

Violencia.
Resumo: 0 estudo identifica e analisa as formas de manifestação da violência de pais, durante os jogos, em torcidas de futsal sub-9. Além disso, analisa as medidas preventivas propostas pelos técnicos. Participaram nove pais, além de três técnicos de três equipes do Rio de Janeiro, um de cada instituição. Os dados foram produzidos por meio de observação participante e entrevistas. A violência simbólica e a violência física manifestaram-se como as formas de violência presentes no grupo analisado. Além disso, as medidas preventivas propostas apontam para a intervenção das equipes multiprofissionais desses clubes, junto aos pais. Logo, concluiu-se que as duas formas de manifestação da violência em torcidas de pais depõem contra os valores do amadorismo esportivo e acabam promovendo comportamentos disfuncionais.

Abstract: The study identifies and analyzes parents' ways of expressing violence while rooting in under-9 futsal matches and examines preventive measures proposed by coaches. Participants were nine parents and three coaches of three teams from distinct institutions in Rio de Janeiro. Data were produced by participant observation and interviews. Both symbolic and physical violence were observed as expressions of violence present in the group analyzed. In addition, the preventive measures proposed point to the intervention by the clubs' multiprofessional teams with parents. Therefore, parents' two forms of expressing violence while rooting go against amateur sports values and end up promoting dysfunctional behaviors.

Resumen: El estudio identifica y analiza las formas en que se manifiesta la violencia de los padres durante los partidos, en las hinchadas de futsal sub-9. Además, analiza las medidas preventivas propuestas por los técnicos. Participaron nueve padres, además de tres técnicos de tres equipos de Rio de Janeiro, uno de cada institución. Los datos fueron producidos a través de observación participante y entrevistas. La violencia simbólica y la violencia física se manifestaron como las formas de violencia presentes en el grupo analizado. Además, las medidas preventivas propuestas apuntan a la intervención de los equipos multiprofesionales de esos clubes junto a los padres. Luego, se concluye que las dos formas de manifestación de la violencia en hinchadas de padres van contra los valores del deporte amador y terminan dando impulso a comportamientos disfuncionales.
*Fundação de Apoio à Escola Técnica do Estado do Rio de Janeiro (FAETEC) Rio de Janeiro, RJ, Brasil. E-mail: marcosjorand@gmail.com

**Programa de Pós-Graduação em Ciências do Exercício e do Esporte da Universidade do Estado do Rio de Janeiro (PPGCEE-UERJ). Rio de Janeiro, RJ, Brasil. E-mail: felipetriani@gmail.com; telles.ntg@ terra.com.br

***Universidade Salgado de Oliveira (UNIVERSO). Rio de Janeiro, RJ, Brasil.

E-mail: muradm@gmail.com; ob.fersantos@oi.com.br

Recebido em: 01-01-2019 Aprovado em: 02-05-2019 Publicado em: 06-06-2019

DOI: https://doi.org/10.22456/1982-8918.89364 (c) (i) () Licence 


\section{INTRODUÇÃO}

O futsal é um esporte vinculado à Fédération Internationale de Football Association (FIFA), com mais de 130 países filiados, praticado em nível formal e não formal, em inúmeros países do mundo. Competições em âmbito regional, nacional e internacional são assistidas e acompanhadas por milhões de pessoas, inclusive pleiteando há mais de uma década tornar-se esporte olímpico (CAVICHIOLLI et al., 2011).

No Brasil, o futsal tem sua prática bastante difundida em diversos espaços sociais. Esse fato justifica-se pela simplicidade do jogo, além do reduzido espaço físico necessário e o uso de equipamentos esportivos relativamente baratos, situações essas adequadas a quaisquer faixas etárias e de alcance possível por diversos segmentos sociais. Adicionalmente, tem grande aceitação devido a seus aspectos competitivos, lúdicos e de socialização. Além disso, apesar de não gozar do mesmo status do futebol, para muitos o futsal é a porta de entrada para o "esporte bretão" (PEDROZA JÚNIOR, 2013).

$\mathrm{Na}$ cultura brasileira, quando um filho começa a praticar um esporte, em especial o futebol, é gerada uma grande expectativa em torno do futuro dessa criança, principalmente em uma perspectiva econômica (CAVICHIOLLI et al., 2011), pois o aumento astronômico nos salários dos jogadores é uma característica dessa modalidade (TAVARES et al., 2018). Somase a isso o desejo do público de ver performances esportivas cada vez mais refinadas (DAMO, 2005). Dessa forma, a busca pelo sucesso na modalidade exige uma dedicação intensa, fazendo com que pais e familiares procurem locais para a aprendizagem da prática esportiva do futebol.

A iniciação esportiva da criança no futsal, em ambiente não escolar, surge, geralmente, na esperança de, em algum momento, receber um convite de clubes de futebol e posteriormente se tornarem jogadores do alto rendimento, ou seja, um planejamento profissional em busca de uma independência financeira (CAVICHIOLLI et al., 2011). No entanto, embora esses anseios existam, Proni (2000) acrescenta que a inserção no futebol tem sido por meio de métodos empresariais, de gerenciamento e marketing de carreiras, muitas vezes mais que a chamada "meritocracia esportiva".

A elevada expectativa sobre o desempenho, a valorização dos resultados e 0 desejo projetivo nos filhos são fatores parentais que podem ser entendidos como mecanismos de pressão (CÔTÉ et al., 2008). Esses comportamentos foram objeto de investigação de Filgueira e Schwartz (2007), que, ao estudarem 20 crianças entre 11 e 12 anos, observaram efeitos negativos sobre o desempenho dos jovens no campo de jogo, efeitos até mesmo inibidores de desempenho, quando houve críticas duras da torcida, principalmente com a ocorrência de gritos e verbalizações constrangedoras.

É possível encontrar evidências (FERLA, 2000) de situações durante os jogos em que os pais chamam a atenção de seus filhos no decorrer da partida, fazendo comentários constrangedores e depreciativos, fato esse que implica a diminuição da autoestima e autoconfiança. Cabe assinalar que o comportamento dos pais durante os jogos tem contribuído para a desistência pelo próprio filho do esporte (CÔTÉ et al., 2008).

OProcesso Civilizatório proposto por Elias (1990; 1994) e utilizado mais especificamente por Elias e Dunning (1995), para compreender as formas de organização social do futebol 
moderno, pode servir como uma ferramenta conceitual para discutir as diferentes formas de manifestação da violência em competições, por parte de pais. Os autores propõem que os processos civilizatórios não são simples, lineares e progressivos, são redes complexas que se manifestam como ondas de múltiplos níveis e que podem ocorrer em plano individual e social.

Assim, adotar essa perspectiva da sociologia do esporte (ELIAS; DUNNING, 1995) pode servir como referencial teórico para compreender os processos "civilizatórios" e "decivilizatórios", presentes no contexto do objeto da investigação em tela. Isso posto, compreender também os comportamentos "civilizatórios" que estabelecem regras, valores do amadorismo como o fair play e a formação das pessoas, bem como os "de-civilizatórios" que depõem contra os valores do amadorismo e manifestam comportamentos disfuncionais (GASTALDO, 2008), pode servir para explicar dialeticamente, ou seja, no nível das contradições humanas, os comportamentos dos pais durante os jogos de futsal.

Portanto, o objetivo deste estudo foi identificar e analisar as formas de manifestação da violência de pais, durante os jogos, em torcidas de futsal sub-9. Além disso, analisar as medidas preventivas propostas pelos técnicos.

\section{MATERIAL E MÉTODOS}

Participaram da investigação pais de atletas e treinadores da categoria sub- $9^{1}$ de futsal, do Fluminense Football Clube, do Clube de Regatas do Flamengo e do Clube de Regatas Vasco da Gama, presentes no Campeonato Estadual de Futsal, no segundo semestre de 2016 e no Campeonato Carioca, no primeiro semestre de 2017. Dessa forma, nove pais foram escolhidos, aleatoriamente, durante os jogos, sendo três de cada clube e, ainda, três técnicos, um de cada clube, perfazendo 12 entrevistados. Assim, na apresentação das narrativas adotouse a expressão "entrevistado" para fazer referência aos pais e "treinador" para os técnicos.

O motivo da escolha dessas equipes se deu por sua relevância social no cenário esportivo do estado do Rio de Janeiro. Cabe esclarecer que o Botafogo de Futebol e Regatas, último integrante dos quatro maiores clubes do Rio de Janeiro, não tinha representação nessas competições. A categoria sub-9 foi escolhida porque o pesquisador principal do estudo trabalha nessa categoria há 18 anos.

Como técnica de coleta de dados foi utilizada a entrevista semiestruturada (LÜDORF, 2017). Nessa perspectiva, o roteiro da entrevista com os pais contou com perguntas sobre 0 nível de cobrança em relação aos filhos, as sensações presentes antes, durante e após os jogos, a percepção sobre atitudes exageradas de pais nas torcidas, seus comportamentos durante os jogos e seus anseios sobre a profissionalização do seu filho.

Já com os técnicos, o roteiro da entrevista foi composto por questões sobre a sua percepção quanto à participação dos pais nos jogos, os comentários emitidos por eles na torcida, a influência da participação deles no trabalho dos técnicos, os alvos dos comentários durante as competições e suas recomendações para lidar com os comportamentos dos pais durante os jogos.

A observação também foi uma técnica de coleta de dados utilizada (LÜDORF, 2017). Dessa maneira, um diário de campo foi utilizado durante a observação, a fim de identificar 0 
palavreado de pais, suas condutas, manifestação de emoções e até mesmo o consumo de bebida alcoólica. A observação foi realizada durante três jogos de cada time, válidos pelas competições organizadas pela federação do Rio de Janeiro, computando um total de nove partidas observadas.

A técnica de análise de conteúdo (BARDIN, 2016) foi utilizada como instrumento de tratamento de dados. Trata-se de uma proposta constituída de três fases: pré-análise, exploração do material e tratamento dos resultados. Desse modo, três unidades de registro emergiram a posteriorià exploração do material, definindo três categorias, sendo elas "violência de força simbólica" 2 , "violência de força física" ${ }^{3}$ e "medidas preventivas".

Cabe sinalizar que este estudo foi realizado de acordo com as normas determinadas pela Resolução do Conselho Nacional de Saúde - CNS 466/12, tendo sido submetido e aprovado pelo Comitê de Ética da Universidade Salgado de Oliveira - UNIVERSO - CAAE: 62261416.6.0000.5289, parecer no: 1.841.283.

\section{RESULTADOS E DISCUSSÃO}

Durante os procedimentos de análise dos dados houve um consenso, entre os pesquisadores, quanto à violência como conceito central orientador da pesquisa, pois foi um "tom vital" muito expressivo em grande parte das narrativas dos pais, bem como nas dos técnicos.

Todos os entrevistados disseram já ter presenciado manifestações de violência durante os jogos, quando questionados sobre as atitudes dos pais na torcida, colocando-a como característica mais evidente no que se refere ao comportamento durante a competição, conforme pode ser observado nas narrativas:

Já presenciei várias vezes ao longo desses anos todos (ENTREVISTADO 2).

Já vi e aconteceu com meu próprio filho, infelizmente, o futebol é uma disputa, mas tem pais que levam isso muito a sério (ENTREVISTADO 7).

Já vi várias vezes, todo jogo sempre tem (ENTREVISTADO 8).

Embora Elias e Dunning (1995) tenham desenvolvido seus estudos tomando por base o contexto europeu, é possível tecer alguns pontos de aproximação no que se refere às manifestações exercidas pelos pais, durante os jogos, em nossa pesquisa, pois os autores indicam que o jogo é explicado como "espaço de guerra". Nele, as equipes adversárias simulam situações de ataque e defesa semelhantes às batalhas campais, manifestam sentimento de confronto, formam grupos e criam quase que "facções", durante a competição. Por aproximação de conteúdos e sentidos, esses elementos também foram identificados durante a observação dos jogos e registrados no diário de campo.

Essa manifestação de explosão eufórica durante os jogos é entendida por Elias e Dunning (1995), como "mimese", sendo a ação de liberar pulsões miméticas. Para os autores, esse fenômeno pode ser observado em Aristóteles ao discutir a ideia de "catarse" na tragédia grega, processo coletivo do teatro grego em que os indivíduos exteriorizavam seus desejos, emoções e euforias. Desse modo, os autores descrevem que, no ambiente do estádio, pessoas

2 Faz referência à coação como ação de constranger, forçar e pressiona o outro (MURAD, 2017).

3 Trata-se da agressão física como o ato de bater, surrar ou causar mal físico a alguém (MURAD, 2017). 
que nunca se permitiram manifestar a falta de respeito com o outro acabam expressando a catarse no seu apogeu, de maneira que se cria uma máscara social, fazendo-as esquecer de suas posturas sociais.

No entanto, considerando a reinterpretação que Murad (2017, p. 77) faz das obras de Elias e Dunning, é possível perceber que a violência pode ser entendida como "opressão, imposição de alguma coisa a outra pessoa ou a outras, por intermédio do emprego da força, qualquer que seja seu tipo". Nesse sentido, a análise dos dados permitiu identificar a manifestação da violência em dois tipos: força simbólica e força física. Então, essas duas manifestações, somadas às medidas preventivas assinaladas pelos técnicos, compuseram as unidades de registro adotadas no estudo em tela, para melhor análise dos resultados.

\subsection{VIOLÊNCIA DE FORÇA SIMBÓLICA}

Ao analisar as narrativas recorrentes dos pais, responsáveis e técnicos sobre situações de "violência de força simbólica" de outros pais nos jogos de futsal, é possível perceber que todos os entrevistados narraram que já observaram cenas de violência durante as competições e que, segundo eles, são fatos recorrentes. Nesse sentido, a seguinte narrativa é um exemplo entre outras semelhantes:

Já presenciei pai brigando grosseiramente com o filho na frente de todo mundo em quadra, já presenciei pai brigando com 0 treinador e brigando com 0 juiz (ENTREVISTADO 2).

A gente está pedindo uma coisa e o pai de fora pedindo outra. Na cabecinha deles, lá com 8/9 anos, fica extremamente conflitante e normalmente pesa o pai, porque é o pai que bota de castigo, o pai que briga, então acaba acontecendo isso (TREINADOR 3).

Para Mutti (2003), muitos pais tentam satisfazer seus desejos não alcançados, por meio do filho, e, dessa forma, estabelecem um alto nível de cobrança às crianças como se fossem adultos em miniaturas. Frequentemente exigem, brigam e têm atitudes violentas com as crianças.

As palavras dos autores corroboram o que foi identificado durante o processo de observação da pesquisa, com destaque para o excesso de valorização dos pais pela vitória de seus filhos, bem como 0 alto nível de cobrança quanto ao bom desempenho nas partidas. Assim, quando as ações não atingiam as expectativas dos pais, foi observado que alguns deles se exaltavam.

Além do registro de observação, as seguintes narrativas também demonstram a manifestação de emoções e euforias:

Uma vez vi um pai reclamando muito com o juiz, depois de um tempo ele se estressou com o técnico, a criança percebeu que era o pai que estava batendo boca, começou a não render dentro de quadra e pediu para sair. Aí o pai começou a brigar com o próprio filho para ele voltar para o jogo, o próprio técnico teve que pedir para ele se acalmar, porque a criança estava chorando no banco de reservas (ENTREVISTADO 1).

A maior parte dos comentários são negativos, o menino erra, o pai xinga, chama de burro, manda fazer direito (TREINADOR 1). 
Somadas à narrativa, as observações feitas durante os jogos permitiram identificar excesso de competitividade entre as torcidas, efeito da alta valorização de desempenho. Além disso, o consumo de bebida alcoólica também foi um comportamento observado. Sobre esse contexto, Elias e Dunning (1995) explicam que o esporte pode ser uma forma de se observar as características da sociedade, pois a percepção do que acontece no esporte como fenômeno social pode ser um caminho para conhecer algumas pistas sobre formas mais abrangentes de relacionamento e comportamento social.

Elias e Dunning (1995) explicam que as brigas dos torcedores podem corresponder a uma forma de exteriorizar e buscar alívio a toda repressão social recebida. Esse fenômeno corresponde a um fator denominado pelos autores como "a busca da excitação", que acontece no tempo livre ou no lazer, pois no tempo livre são permitidas sensações que o mundo das obrigações não aceita, por isso a sua importância no processo civilizatório (GEBARA, 2000). A permissão e a expressão dessas sensações levam o indivíduo a ser o agente principal nos momentos de lazer. Contudo, no mundo das obrigações, as convenções sociais se impõem aos indivíduos e assim subestimam a capacidade do agente social, criando uma série de ações morais e clichês. Já no mundo do lazer, o sujeito se desvincula dessa moral totalitária para uma moral "um pouco menos regrada", menos repressora e um pouco mais livre.

Embora a "violência de força simbólica" tenha sido objeto da narrativa dos pais, ao fazer referência a outros pais, não são somente esses personagens que manifestam essa violência, pois também foram identificados casos de técnicos, que, de forma semelhante, exerciam a "violência de força simbólica". A narrativa a seguir reforça essa asserção.

Quando meu filho perdeu uma bola e tomou um gol, imediatamente o treinador tirou ele com palavras grosseiras e sem pedagogia nenhuma, aí eu realmente saí de mim, dei a volta na quadra e fui lá no banco aonde eles estavam e reclamei de maneira agressiva com o treinador, que não falou nada. Ainda falei para o meu filho que fosse a última vez que chorasse num jogo (ENTREVISTADO 3).

Mello (2016), ao estudar a prática pedagógica do professor no ensino do esporte, percebeu uma forma de violência simbólica intitulada de "prática autoritária", que se refere às ações do professor contra o aluno, por meio do autoritarismo, da punição e da hostilidade, muitas vezes aleatória. De acordo com a investigação, a violência do professor sobre o aluno acontecia quando ocorriam erros no jogo, quando o resultado da partida não era positivo e quando os alunos demonstravam "comportamentos de ociosidade".

Crespan e Ahlert (2015) esclarecem que a maior manifestação de violência simbólica que o professor pode exercer sobre os alunos é a utilização exagerada de seu poder, exigindo que sejam reprodutores de performances técnicas, como no esporte de alto rendimento. Triani (2016) explica que requerer o alto rendimento somente deve ser uma prática quando o esporte é praticado em sua dimensão de rendimento, sendo o atleta remunerado e reconhecido como profissional do esporte. Dessa forma, quando o cenário for diferente, com crianças e praticantes muito jovens, o que deve prevalecer são os princípios do esporte de participação.

Embora a "violência de força simbólica" seja manifestada durante os jogos, algumas narrativas desvelam sentimentos de arrependimento após as partidas.

Me arrependo de tanta coisa, meus erros de ficar gritando e cobrando dele, quando os jogos acabavam, eu não me perdoo, até deprimido eu fiquei (ENTREVISTADO 9). 
Muitas vezes, um dos motivos para existência de comportamentos violentos por parte dos pais pode ser por não concordar com as decisões dos árbitros, dos treinadores ou quando seus filhos são criticados. De acordo com DaMatta (1982), a vendeta seria a justiça pelas próprias mãos, por meio de comportamentos violentos. Esse tipo de comportamento não deixa de ser uma revolta moral contra uma situação vivida e percebida como injustiça.

Depois de um jogo, eu me aborreci com o preparador do meu filho e alguns pais; me arrependi entre aspas, porque é sempre ruim quando você perde o seu limite, mas na época foi necessário, porque estava ocorrendo muita injustiça com meu filho, mas me arrependi um pouco (ENTREVISTADO 1).

A meu ver, os pais querem ajudar muito, mas no final acabam é atrapalhando nosso trabalho. A parte emocional também interfere muito, pois eles acabam se exaltando com as crianças e com a arbitragem (TREINADOR 2).

May (1981) afirma que a violência é relacionada com o poder inerente a todas as relações humanas, sendo necessário que se interprete como uma reação para conquistar o sentimento de significação. Sempre que existir uma relação de opressão entre indivíduos ou grupos de indivíduos, a violência reativa será a resposta possível daqueles que se sentem oprimidos e submetidos a grande tensão.

\title{
3.2 VIOLÊNCIA DE FORÇA FÍSICA
}

A análise do conteúdo das narrativas permitiu identificar também a manifestação da violência de força física, conforme as palavras dos entrevistados.

\begin{abstract}
Já vi pai dando bronca no filho dentro da quadra, já vi pai entrar na quadra para agredir juiz, já vi pai agredindo árbitro, a criança dentro da quadra chorando, já vi briga na torcida por causa de pais, já vi de tudo (ENTREVISTADO 4).
\end{abstract}

Tem um pai que entrou na quadra para agredir 0 árbitro da partida e acabou batendo num rapaz da comissão técnica do adversário, com isso começou uma briga generalizada, caso da polícia chegar no ginásio (ENTREVISTADO 8).

Uma vez eu estava saindo do treino, eu e meu filho, eu estava dando uma bronca no meu filho, porque ele treinou mal, quando vimos um pai do sub-11 batendo na criança, no próprio filho, e o moleque era bom, jogava muito bem (ENTREVISTADO 9).

Se, por um lado, essa é a manifestação moderna da prática do futebol, que Elias intitulou de "processo civilizatório"4, por outro, o retrocesso e os comportamentos disfuncionais durante os jogos representam o que chamou de "processos de-civilizatórios", movimento, tendência mundial, que vem se manifestando desde os anos de 1960, ocasião em que há aumento da violência e consequentemente do hooliganismo (GASTALDO, 2008).

O aumento da manifestação da violência, para Dunning (GASTALDO, 2008), está no resultado da absorção do esporte pela perspectiva do profissionalismo, que mistura os valores da prática esportiva com aqueles orientados pelo dinheiro, bem como pela manifestação de atitudes como as de "vencer a qualquer custo", mecanismos que aumentam a pressão sobre os esportistas, ficando, assim, difícil a sobrevivência dos valores do amadorismo, como o fair

\footnotetext{
4 Embora o conceito de "processo civilizatório" seja mais amplo que a referência ao futebol, na obra utilizada no presente manuscrito como referencial teórico, logo em sua introdução, Elias (1995, p. 39) escreve "quando iniciamos este estudo, a sociologia do desporto dava os primeiros passos [...]. Dunning debateu comigo a questão de saber se o desporto, e particularmente o futebol, poderia ser considerado um tema de investigação respeitável".
} 
play. Adicionalmente, cabe lembrar Triani (2016) quando assinala que no esporte moderno a violência aumentava à medida que as apostas de dinheiro foram sendo uma prática cultural dentro do contexto esportivo.

O exercício da violência pode resultar em problemas físicos, psicológicos e sociais que não necessariamente levam a lesões, invalidez ou morte (KRUG et al., 2002). Dunning (GASTALDO, 2008) lembra os casos de dois jogadores mais bem pagos de seu tempo, os ingleses George Best e Paul Gascoigne, que não suportaram a alta pressão midiática e, não conseguindo lidar com a súbita fama e riqueza, tornaram-se alcoólatras crônicos.

Diante desses entendimentos, as atitudes narradas pelos entrevistados podem estar associadas ao excesso de expectativa criada pelos pais, pois no momento em que as coisas não acontecem da maneira que eles desejam, passam a brigar e até mesmo bater nas crianças, conforme a seguinte narrativa:

Já presenciei, depois de acabar um jogo, o pai vir e dar uma tapa num menino de 7 anos, porque ele não tinha jogado bem (ENTREVISTADO 6).

É possível afirmar que não existe uma única causa que explique o fato de pessoas se comportarem de modo violento com outras, ou de alguns locais terem mais violência que outros. Desse modo, as ações de violência podem ser caracterizadas por uma complexa interação de fatores individuais, de relacionamento, sociais, culturais e ambientais. Assim, é assinalado que conhecer como esses fatores estão associados à violência é um dos passos mais importantes para prevenção da sua manifestação (KRUG et al., 2002).

A observação registrada no diário de campo permitiu perceber que as ofensas e 0 consumo de bebidas alcoólicas são comportamentos que podem intensificar a manifestação da violência. Um desses dados também está registrado em narrativa:

Teve uma vez que os pais xingaram nossos filhos e a gente partiu para agressão, mas graças a Deus não teve briga, porque as pessoas separaram (ENTREVISTADO 8).

Elias e Dunning (1995) explicam esses comportamentos como uma forma de alívio das repressões sociais, que os indivíduos recebem por imposição da sociedade ao longo de todo o tempo de sua existência social. Nessa mesma perspectiva, Almeida (2003) explica que enquanto no mundo das obrigações as convenções sociais subestimam a capacidade do agente social, criando uma série de ações morais e clichês, no mundo do lazer o sujeito se desvincula dessa moral totalitária para uma moral "um pouco menos regrada". Assim, observase, como exemplo, a prática de xingamentos e consumo elevado de bebidas alcoólicas, ações que afastam, por alguns instantes, o peso de viver em uma "sociedade moralizante".

Elias e Dunning (1995) destacam que é no ambiente do estádio que a catarse se expressa no seu apogeu, levando pessoas que nunca se permitiram excessos, como xingar alguém, a se liberar das amarras sociais. A massa eufórica serve como máscara social do sujeito que se esconde atrás de um símbolo (time de futebol), ocasião em que o grupo se apropria coletivamente do papel de torcedor, esquecendo todas as outras posturas sociais, como pai, filho, marido, mulher, trabalhador, empresário, operário.

Portanto, fazendo um paralelo com os resultados de Elias e Dunning (1995), percebe-se que os ginásios de futsal também podem ser um ambiente em que o lazer funciona como uma atividade de mimese e, por consequência, de prazer. Dessa maneira, os pais que normalmente formam grupos que interagem nos treinos, festas e principalmente nos finais de semana, nos 
jogos de seus filhos, podem, por assim dizer, "se transformar". Com isso, considerando os estudos desses autores, no momento em que estão torcendo pelos seus filhos, pode haver uma alteração de imagem pública, já que, por vezes, manifestam-se de modo bem distinto daqueles anteriormente predominantes em seu cotidiano.

\subsection{MEDIDAS PREVENTIVAS}

Analisando o conteúdo das narrativas, principalmente a dos treinadores, uma categoria emergente foi "medidas preventivas", pois ficou nítido, como um anseio desses agentes, a necessidade de algum tipo de intervenção para modificar o cenário vivenciado por eles nos jogos. Nesse contexto, apesar dos técnicos reconhecerem que o envolvimento dos pais é fundamental, argumentam que é comum o seu comportamento inadequado nos jogos e treinos.

As atitudes erradas podem ir desde um destempero com seu filho após uma derrota ou um mau desempenho, até brigas entre pais de atletas, com a arbitragem, por não concordar com suas decisões (TREINADOR 2).

Os pais que tomam esse tipo de atitude podem não saber o quanto e como estão influenciando seus filhos. Dessa maneira, o objetivo da iniciação esportiva deve estar sendo mal entendido pelos pais, pois mais importante do que buscar o desempenho competitivo, o resultado, a vitória, o esporte deve estar a serviço da formação dos jogadores para 0 exercício de uma cidadania minimamente consciente de direitos e deveres, da necessidade do cumprimento de regras e aceitação de limites.

Nessa perspectiva, o início da prática esportiva, na infância, jamais deve ser semelhante ao de adultos, pois crianças não têm as mesmas habilidades e não conseguem se relacionar taticamente com os demais membros da equipe e nem mesmo entender a codificação de todas as regras do esporte (SULLIVAN; ANDERSON, 2004).

O processo de iniciação no esporte precisa estar bem esclarecido para os pais, pois pode ser o principal responsável pela boa formação, mas também gerador de possíveis traumas na infância (MOREIRA, 2003). Adicionalmente, Estigarribia (2005) assinala que esse acontecimento tem grande possibilidade de estar relacionado com a mentalidade competitiva dos pais ao cobrarem resultados equivalentes aos de atletas. Nesse sentido, a supervalorização das competições e a busca incessante por vitórias têm como efeito certa pressão gerada pelos pais e outros adultos, desvelando-se como um fator negativo ao processo de iniciação esportiva (RODRIGUES; SOUSA; MACEDO, 2010).

Os treinadores entrevistados também afirmaram que o esporte pode oportunizar mudanças de pensamentos, ações e condutas dos pais, através de um trabalho de conscientização, por parte dos agentes envolvidos nesse processo, pois para eles:

Muitos pais não sabem nem que estão prejudicando seus filhos nos jogos. Se houvesse um trabalho específico com eles, com certeza iriam ter outras atitudes (TREINADOR 3).

Assim como o garoto está iniciando na prática esportiva, o pai também está; eu considero ele como fosse um garoto de sub-9. Então, a comissão e a coordenação, assim que montasse a equipe, deveria reunir os pais falar do comportamento deles dentro de quadra até para diminuir a pressão no filho e da própria equipe (TREINADOR 2). 
Novikoff, Costa e Triani (2012), ao revisitaram a literatura, encontraram que a intervenção do treinador e dos pais pode ser decisiva, como medida preventiva, para evitar frustrações e até lesões, sendo o sucesso na iniciação esportiva alcançado por meio do respeito às características das crianças e de seu desenvolvimento.

Nesse contexto, algumas sugestões dos treinadores foram destacadas, a fim de prevenir os comportamentos inadequados dos pais, para que, consequentemente, sejam minimizadas as atitudes de violência no contexto esportivo: "Os clubes tinham que apresentar algumas palestras para explicar aos pais que eles podem desempenhar um papel altamente positivo ou negativo na experiência esportiva das crianças, mas este trabalho não existe." (TREINADOR 1).

De fato, nas entrevistas e nas observações, percebeu-se a inexistência de um trabalho específico de orientação para pais. $O$ que há são intervenções pontuais, quando alguns pais se excedem. Então, cabe lembrar Murad (2009, p. 114), ao assinalar que "[...] o esporte pode ser educativo ou reeducativo, porque ajuda na preparação das pessoas para conviverem e respeitarem o outro, o que é uma vivência de cidadania". Portanto, uma intervenção junto aos pais poderia contribuir para esclarecer sobre a função da iniciação esportiva, diminuindo a ansiedade quanto aos resultados competitivos e aumentando a percepção no que se refere à formação da pessoa.

Dunning, em entrevista concedida a Gastaldo (2008), ressalta que é preciso discutir a questão "civilizatória" dos esportes proposta por Elias, pois para o sociólogo do esporte essa operacionalização depende da inculcação nos jovens, desde a infância, dos valores do amadorismo, como é o caso do fair play e do jargão de que "competir é mais importante do que vencer".

Também foi sugerida outra medida preventiva: "Eu tenho uma posição que poderia ser meio impactante, chocante no primeiro momento, que seria a proibição de ver os treinos" (TREINADOR 2). Para ele, os pais ficam vendo os treinos e analisando se o filho está titular ou reserva, se o treinador está certo ou errado. Com isso, os que não estão satisfeitos já vão para os jogos com a intenção de reclamar. $O$ treinador justifica sua medida preventiva, por meio da seguinte narrativa:

Acho que uma medida assim poderia melhorar, porque sem saber o que está acontecendo ele ficaria menos estressado, por mais que o filho passasse alguma coisa, ele ia na expectativa sem saber o que está acontecendo, entendeu? (TREINADOR 2).

No contexto do futsal, todos os clubes permitem que os familiares assistam ao treinamento, motivo pelo qual o técnico afirma que seria "uma medida impactante". Acredita-se que essa medida seria de difícil aplicação devido principalmente à idade das crianças. A sugestão oferecida pelo treinador aponta como às vezes a presença dos pais é nociva, levando o profissional a preferir a ausência deles ao longo dos treinamentos. Desse modo, cabe lembrar Dunning (GASTALDO, 2008), quando assinala que os distúrbios vinculados à massa nos estádios também deveriam ser vistos como um problema das autoridades do futebol e não somente como responsabilidade das políticas regionais ou nacionais.

\section{CONCLUSÃO}

Violência de força simbólica e violência de força física emergiram por meio de comportamentos "de-civilizatórios", bem como reclamações durante os jogos, xingamentos, 
agressões verbais, agressões físicas e instruções aos jogadores durante as competições de forma pejorativa e invasiva. Nesse sentido, faz-se necessário ressaltar a importância dos pais no "processo civilizatório", pois no ambiente competitivo a família deve oferecer afeto, compreensão e incentivo, para que os jovens possam ter suporte em suas carreiras esportivas. Além disso, destaca-se que, embora a família seja considera "torcida", seu comportamento pode ser diferente do apresentado pela torcida tradicional, isto é, o de controle das emoções, elemento central do referencial teórico que norteou a pesquisa, na busca de um esporte mais civilizado e com menos descontrole.

Quanto às medidas preventivas, se observou que os clubes não apresentam uma proposta de assessoramento e conscientização aos pais, a fim de mostrar quais são os comportamentos adequados para a prática de uma relação saudável no meio esportivo. Essa proposta pode oferecer estratégias para minimizar as diferentes manifestações de violência, sendo interessante o desenvolvimento de intervenções, como projetos, seminários, palestras e parcerias, a fim de apresentar aos pais a relação pedagógica, social e ética, relativa aos valores do esporte, para a formação do indivíduo como cidadão. Portanto, tornase indispensável a promoção de ambientes saudáveis de convivência entre técnicos, pais, crianças e coordenadores esportivos, para que os jovens tenham um desenvolvimento integral no processo civilizador por meio do esporte.

\section{REFERÊNCIAS}

ALMEIDA, Marco Antonio Bettine de. Lazer e reclusão: contribuições da teoria da ação comunicativa. 2003. 158f. Dissertação (mestrado) - Universidade Estadual de Campinas, Faculdade de Educação Física, Campinas, SP, 2003.

BARDIN, Laurence. Análise de conteúdo. Lisboa: Edições 70, 2016.

CAVICHIOLLI, Fernando Renato; CHELUCHINHAK, Aline Barato; CAPRARO, André Mendes; MARCHI JÚNIOR, Wanderley; MEZZADRI, Fernando Marinho. O processo de formação do atleta de futsal e futebol: análise etnográfica. Revista Brasileira de Educação Física e Esporte, v. 25, n.4, p.631-647, 2011.

CÔTÉ, Jean; STRACHAN, Leisha; FRASER-THOMAS, Jessica. Participation, personal development, performance through youth sport. In: HOLT, Nicholas. Positive youth development through sport. London: Routledge, 2008. p. 122-140.

CRESPAN, Alana Grünewald; AHLERT, Alvori. Agressividade e violência na escola: olhares sobre a educação física. Caderno de Educação Física e Esporte, v. 13, n. 2, p. 71-84, 2015.

DAMATTA, Roberto. As raízes da violência no Brasil: reflexões de um antropólogo social. In: PAOLI, Maria Célia; BENEVIDES, Maria Victoria; PINHEIRO, Paulo Sérgio; DAMATTA, Roberto. A violência brasileira. São Paulo, Brasiliense, 1982. p. 11-44.

DAMO, A. S. Do dom à profissão: uma etnografia do futebol de espetáculo a partir de formação de jogadores no Brasil e na França. 2005. 435f. Tese (Doutorado em Antropologia Social) - Instituto de Filosofia e Ciências Humanas, Universidade Federal do Rio Grande do Sul, Porto Alegre, 2005. 
ELIAS, Norbert. 0 processo civilizador: formação do estado e civilização. Rio de Janeiro: Zahar, 1990.

ELIAS, Norbert. 0 processo civilizador: uma história dos costumes. Rio de Janeiro: Zahar, 1994.

ELIAS, Norbert; DUNNING, Eric. A busca da excitação. Lisboa: Difel, 1995.

ESTIGARRIBIA, Rodrigo Casares. Aspectos relevantes na iniciação ao futsal. Trabalho de Conclusão de Curso (Educação Física). 2005. 56f. Universidade Católica do Rio Grande do Sul. Porto Alegre, 2013.

FERLA, Michael. Análise da natureza e alvo dos comentários feitos por pais durante a situação de competição infantil. 2000. 64f. Trabalho de conclusão de curso (Educação Física). -Universidade Estadual de Londrina, Londrina, 2000.

FILGUEIRA, Fabrício; SCHWARTZ, Gisele. Torcida familiar: a complexidade das inter-relações na iniciação esportiva ao futebol. Revista Portuguesa de Ciências do Desporto, v. 7, n. 2, p. 245-253, 2007.

GASTALDO, Édison. Esporte, violência e civilização: uma entrevista com Eric Dunning. Horizontes Antropológicos, v. 14, n. 30, p. 223-231, 2008.

GEBARA, Ademir. Norbert Elias e a teoria do processo civilizador. In: BRUHNS, Heloisa. (Orgs). Temas sobre o Lazer. Campinas: Autores Associados, 2000. p. 112-135.

KRUG, Etienne; DAHLBERG, Linda; MERCY, James; ZWI, Anthony; LOZANO, Rafael. World report on violence and health. Geneva: World Health Organization, 2002.

LÜDORF, Silvia. Metodologia da Pesquisa: do projeto ao trabalho de conclusão de curso. Curitiba: Appris, 2017.

MAY, Rollo. Poder e inocência: uma análise das fontes de violência. Rio de Janeiro: Zahar, 1981.

MELLO, Tiago Lepre. A origem da violência nas aulas de educação física: a prática pedagógica do professor. 2016. 195f. Dissertação (Mestrado em Educação) - Universidade Federal de São Carlos, 2016.

MOREIRA, Sandro Marlos. Pedagogia do esporte e o karatê-dô: considerações acerca da iniciação e da especialização esportiva precoce. 2003. 233 f. Dissertação (Mestrado em Educação Física) - Faculdade de Educação Física, Universidade Estadual de Campinas, Campinas, 2003.

MURAD, Maurício. Sociologia e educação física: diálogos, linguagens do corpo, esportes. Rio de Janeiro: FGV, 2009.

MURAD, Maurício. A violência no futebol: novas pesquisas, novas ideias, novas propostas. 2.ed.rev. ampl. São Paulo: Selo Benvirá; Saraiva, 2017.

MUTTI, Daniel. Futsal: da iniciação ao alto nível. 2. ed. São Paulo: Phorte, 2003.

NOVIKOFF, Cristina; COSTA, Luiz Fernando; TRIANI, Felipe. Os efeitos da iniciação esportiva na vida de crianças: o que a literatura vem apontando. EFDeportes.com, Revista Digital, Buenos Aires, v. 17, n. 173, 2012. Disponível em: <https://www.efdeportes.com/efd173/os-efeitosda-iniciacao-esportiva.htm>. Acesso em: 20 ago. 2018. 
PEDROZA JÚNIOR, Edvaldo Torres. Processo de seleção e captação de atletas de futebol de campo na categoria sub-15 em Pernambuco. Revista Brasileira de Futsal e Futebol, v. 5, n, 16, p. 155-163, 2013.

PRONI, Marcelo. A metamorfose do futebol. Campinas: Editora Unicamp, 2000.

RODRIGUES, Divina Aparecida; SOUSA, Maria Aparecida; MACEDO, Márvio Marcelo. A relação entre especialização precoce e o abandono prematuro da natação em Uberlândia, MG. EFDeportes.com, Revista Digital. Buenos Aires - Ano 14, n. 140, 2010. Disponível em: shttps:// www. efdeportes.com/efd140/especializacao-precoce-e-o-abandono-prematuro-na-natacao.htm $>$. Acesso em: 10 out. 2018.

SULLIVAN, Andy; ANDERSON, Steven. Cuidados com o Jovem Atleta: enfoque interdisciplinar na iniciação e no treinamento esportivo. Barueri: Manole, 2004.

TAVARES, Ana Beatriz; VOTRE, Sebastião Josué; TELLES, Silvio de Cassio Costa; DEVIDE, Fabiano. Estádio do Maracanã: percepções a partir da reestruturação arquitetônica de 2010. Revista Brasileira de Ciências do Esporte, v. 40, n. 2, p. 205-212, 2018.

TRIANI, Felipe. Esporte e Sociedade: da prática esportiva antiga à contemporânea. In: TRIANI, Felipe; PIMENTEL, Paulo (org.). Esporte, Educação Física e Sociedade. Rio de Janeiro: Autografia, 2016. p. 11-26. 